Chapter 18.

\title{
Handling, Cooling and Sanitation Techniques for Maintaining Postharvest Quality ${ }^{1}$
}

\author{
S.A. Sargent, M.A. Ritenour and J.K. Brecht ${ }^{2}$
}

More than half of Florida-grown vegetables are shipped out of state, and an increasing amount is being exported to Canada, the Caribbean, Europe and the Pacific Rim countries. To successfully compete in these distant markets, Florida shippers must overcome the detrimental effects of longer shipping times on produce quality. With such a dependence on distant markets, packers and shippers are necessarily concerned with methods and technologies that minimize postharvest losses, since estimates for produce losses during wholesale and retail handling alone range from $9 \%$ to $16 \%$.

Successful postharvest handling of vegetable crops requires careful coordination and integration of the various steps from harvest operations to consumer level in order to maintain the initial product quality. Horticultural quality refers to those characteristics that consumers associate with each commodity and which are dependent upon the particular end-use, such as sweetness in strawberries and melons, tenderness in snap beans and sweetcorn, and crispness in carrots and celery. Quality also refers to freedom from defects such as blemishes, mechanical injury, physiological disorders, decay, and water loss. It is important to keep in mind that quality loss in fresh vegetables is cumulative: each incident of mishandling reduces final quality at consumer level.

Several factors reduce quality during postharvest handling, including:

- harvest at the incorrect maturity stage

- careless handling at harvest and during packing and shipping

- poor sanitation

- delays to cooling or sub-optimal cooling

- shipping/storage above or below optimal temperature

- lack of proper relative humidity

- for some commodities, exposure to ethylene gas

Numerous technologies and procedures can significantly reduce the rate of quality losses during handling. These include the use of drying, curing, temperature conditioning, disinfestation (for exports/imports), ethylene treatment, application of surface coatings, sanitation treatments, controlled atmosphere storage and shipping, and modified atmosphere packaging. These applications are, in many cases, crop-specific.

Two of the most important means for maintaining vegetable quality during postharvest handling are minimizing mechanical injury and managing temperature. Proper handling and temperature management will significantly reduce losses due to decay and accelerated senescence. With vegetables typically being handled several times from harvest to retail level, it is critical that personnel at each step be properly trained and supervised.

This chapter will focus on methods and techniques for reducing losses in postharvest quality during typical commercial handling operations.

\section{MINIMIZING POSTHARVEST LOSSES}

\section{Causes}

Fruits and vegetables undergo a number of transfers during harvest, handling, packing and shipping operations. Each of these transfer points has the potential to reduce quality and therefore, subsequent postharvest life, by inflicting injuries such as bruises, cuts, punctures and abrasions. Mechanical injury has been determined by the USDA to be the leading cause of quality loss at wholesale and retail levels for head lettuce, potatoes and strawberries. The primary cause of loss for Florida and California tomatoes at retail and consumer levels was found to be parasitic disease; however, the predominant decay organisms present were those that require mechanical injury for infection to occur. Minimizing mechanical injury, therefore, should be one of the primary goals of produce handlers during postharvest operations.

Following harvest, vegetables lose firmness due to senescence processes, ripening, and water loss. As a result, they become increasingly susceptible to mechanical injury. In controlled laboratory studies we have found that tomatoes are quite sensitive to a physiological disorder known as internal bruising. Internal bruising is a latent disorder, which means that it only becomes apparent after the tomato reaches the full-red ripeness stage. It develops when a tomato receives an impact above the locule during 
Table 1. Effect of ripeness stage and drop height on incidence of internal bruising of tomatoes ('Solar Set'). Two drops on opposite sides.

\begin{tabular}{|c|c|c|c|c|c|c|}
\hline \multicolumn{2}{|c|}{ Green Stage } & \multirow{2}{*}{$\begin{array}{l}\text { Number of } \\
\text { Tomatoes }\end{array}$} & \multirow{2}{*}{$\begin{array}{l}\text { Fruit with Internal } \\
\text { Bruising }(\%)^{z}\end{array}$} & \multicolumn{3}{|c|}{ Internal Bruising Severity Rating $(\%)^{y}$} \\
\hline $\mathrm{cm}$ & inches & & & Slight & Moderate & Severe \\
\hline 0 & 0 & 20 & 0.0 & 0.0 & 0.0 & 0.0 \\
\hline 10 & 4 & 20 & 5.0 & 0.0 & 0.4 & 0.0 \\
\hline 20 & 8 & 20 & 5.0 & 5.4 & 0.7 & 0.0 \\
\hline 30 & 12 & 20 & 45.0 & 0.0 & 8.5 & 1.8 \\
\hline \multicolumn{7}{|c|}{ Breaker Stage } \\
\hline 0 & 0 & 15 & 0.0 & 0.0 & 0.0 & 0.0 \\
\hline 10 & 4 & 15 & 73.0 & 0.0 & 10.4 & 5.5 \\
\hline 20 & 8 & 15 & 100.0 & 0.0 & 22.2 & 6.7 \\
\hline 30 & 12 & 15 & 100.0 & 0.0 & 8.2 & 24.3 \\
\hline
\end{tabular}

harvest or handling. The impact disrupts normal ripening in the locular gel, and at full ripeness stage, the gel is a cloudy, yellowish-green color instead of a clear and red color. Tomatoes dropped at breaker ripeness stage $(<10 \%$ red color) developed more internal bruising than those dropped at green stage. Of breaker stage tomatoes dropped once from $10 \mathrm{~cm}$ (4 inches) onto an unpadded surface, $73 \%$ later showed internal bruising, whereas only 5\% of tomatoes dropped at green stage developed the disorder (Table 1). This information should be applied to the design of packing lines since tomatoes typically receive multiple drops in excess of this height during handling and packing operations.

Mechanical injuries hasten senescence and ripening as well as provide infection sites for decay organisms (Fig. 18-1). Therefore, vegetables must be carefully handled during harvest, packing and shipping operations to minimize bruising, cuts, punctures and abrasions. Sorting and grading operations are also critical; workers must be thoroughly trained and supervised to ensure removal of injured vegetables, which could later develop decay during shipping. Sources of mechanical injury in several handling operations follow.

\section{Harvest Operations}

Harvest operations require the use of appropriate harvest containers and constant management of labor. Workers should be instructed to harvest with appropriate techniques for the particular crop, to trim fingernails, and be monitored to verify proper handling. There should be a system to reward workers for careful handling. Harvest containers and bulk bins should have smooth sides and be kept free of debris; picking containers should be carefully emptied into field bins. Harvest containers should be cleaned and sanitized prior to reuse. Farm lanes should be kept level and field trucks should be equipped with air suspension instead of spring suspension to dampen vibrations and reduce impacts during transport.

\section{Packing Operations}

Methods of transferring product from one component to another during packing operations also influence the incidence of mechanical injury, such as:

- drops to unpadded surfaces

- protrusions at impact surfaces

- directional changes in product flow

- unmatched speeds of adjoining components

- excessive transfer plate angles

- excessive rotational velocities of brushes and rollers

- excessive line speed due to undersized capacity

Reducing mechanical injury involves minimizing drops and rolls at transfer points on the packing line. To achieve this, packing lines should be designed to be straight and have minimal changes in height between components. Installation of suspended curtains over conveyors at sorting tables can reduce impact forces by $50 \%$. Container filling is a critical operation and must be carefully monitored. Produce can be crushed during closure of an overfilled container, and punctured during stapling, while under filling of the container can result in severe mechanical injury due to jostling during shipping and handling.

\section{SANITATION OF RECIRCULATED WATER}

Pathogens present on freshly harvested vegetables accumulate in water handling systems such as dump tanks, flumes and hydrocoolers in which the water is recirculated. Even healthy looking products coming in from the field can harbor large populations of pathogens, particularly during warm, rainy weather. When vegetables are immersed in water containing pathogens they can become infected and decay during shipping and handling.

Many postharvest decay problems result from the incorrect use of chlorine for sanitizing packinghouse dump 
tanks and hydrocoolers. In our experience, although many packers routinely add chlorine to their water handling systems, the effectiveness of this treatment in reducing postharvest decay can be decreased or even nonexistent through failure to follow the UF/IFAS guidelines for packinghouse water sanitation. The current recommendation is constant maintenance of 100 to 150 parts per million of free (available) chlorine and a $\mathrm{pH}$ in the range of 6.8 to 7.2 for all recirculated water. Whenever a product is dumped into water or washed with recirculated water that is not maintained under these conditions there is a good probability that decay problems will arise during handling and shipping. Proper water sanitation will also serve to kill many human pathogens that can cause food poisoning.

The first requirement in maintaining water sanitation is the addition of an approved sanitizer to the water, such as sodium hypochlorite, calcium hypochlorite or liquid chlorine, to prevent the accumulation of pathogens. The effectiveness of chlorinated water as a sanitizer is greatly affected by the $\mathrm{pH}$ of the solution. If the $\mathrm{pH}$ is too high (above 8.0), the chlorine acts slowly and a higher concentration is necessary to achieve a rapid kill of the pathogens in the water. In contrast, if the $\mathrm{pH}$ is too low (below 6.5), then the chlorine is too active; it is more corrosive to equipment and effective chlorine concentrations are difficult to maintain. All recirculated water should be changed on a daily basis, or more frequently if the water becomes extremely dirty due to build up of organic matter. Local environmental codes must be consulted for proper disposal of chlorinated water.

The second and also necessary requirement is to maintain the free (also called available or unreacted) chlorine concentration at all times during use. The chlorine product must be added to the water to replace the chlorine lost to reactions with organic matter, chemicals, microorganisms, as well as the surfaces of vegetables (known as the chlorine demand). There are several ways to maintain adequate chlorine concentrations. Automated systems are commonly used to monitor the oxidation-reduction potential (ORP) and correlate that reading to free chlorine concentration as well as monitor water $\mathrm{pH}$. These systems add a chlorine product to the water to replace that which is lost to reactions in the water and adjust $\mathrm{pH}$ as necessary according to setpoint settings. Other less sophisticated systems automatically dispense chlorine products, but frequent manual measurement of the free chlorine concentration is required to know if the proper amount of chlorine is being added. Packinghouse managers must be vigilant with these latter systems because the chlorine demand can change abruptly, such as with the addition of product from a different field, a different grower, or a different field crew. If free chlorine measurements are not taken often enough, free chlorine levels in the water can quickly dissipate, causing the product to become infected with decay pathogens from the water. Manual addition of chlorine products can be used, again if the manager is diligent about taking free chlorine and $\mathrm{pH}$ measurements and making the necessary adjustments. Samples should be taken at least on an hourly basis.

Other factors that affect chlorine efficacy include the initial level of inoculum present on the vegetable surface and the exposure time of the crop in the water. In the case of tomato dump tanks, the water should be heated $10^{\circ} \mathrm{F}$ (about $6^{\circ} \mathrm{C}$ ) above the pulp temperature to reduce infiltration of the water (and pathogens) into the tomatoes. The tomatoes should not be in the tank for more than 3 minutes or submerged more than a few inches to minimize infiltration.

Packinghouse managers must be vigilant in maintaining water quality in handling systems. By following these simple guidelines, postharvest decay problems should be drastically reduced.

\section{Choice of Sanitizer}

Proper sanitation of water (especially recirculated water) used in dump tanks, hydrocoolers, etc. of fresh vegetable packinghouses is important for delivering sound produce to the consumer. Not only do unsanitary conditions promote direct product loss through decay, but also rising food safety concerns about human pathogens are becoming increasingly important to consumers. Because water is one of the best carriers of pathogens, it must be treated (either chemically or physically) to prevent the accumulation of pathogens in the water and prevent cross-contamination of sound produce. Such treatments are not particularly effective at reducing pathogen levels already on the surface of the produce; it is much more effective to prevent contamination in the first place. This means following Good Agricultural Practices regarding water quality, use of manure and municipal biosolids, harvesting practices, and worker, field, and packing facility sanitation.

Although chlorine is currently the sanitizer of choice for most vegetable packinghouses, other chemicals have been approved by the Environmental Protection Agency (EPA) for contact with food products. The following are some of the approved antimicrobial chemicals and a discussion of advantages and disadvantages of using each (Table 2).

Chlorine. Chlorine is currently the predominant method used by packinghouses to sanitize water systems. The main advantages to using chlorine are that it is effective at killing a broad range of pathogens and that it is relatively inexpensive. It also leaves very little residue or film on surfaces. However, chlorine is corrosive to equipment and $\mathrm{pH}$ must be monitored and adjusted often to maintain chlorine in its active form. Continual addition of chlorine without changing the water can result in the accumulation of high salt concentrations that may injure some produce. Further, chlorine can react with organic matter to form small amounts of different trihalomethanes (THMs) that are thought to be carcinogenic. However, the relative risks 
Table 2. Sanitizing Chemicals for Packinghouses.

\begin{tabular}{|c|c|c|}
\hline Compound & Advantages & Disadvantages \\
\hline $\begin{array}{l}\text { Chlorine } \\
\text { (Most widely used } \\
\text { sanitizer in packinghouse } \\
\text { water systems.) }\end{array}$ & $\begin{array}{l}\text { Relatively inexpensive. } \\
\text { Broad spectrum - effective on many different } \\
\text { microbes. } \\
\text { Practically no residue left on the commodity. }\end{array}$ & $\begin{array}{l}\text { Corrosive to equipment. } \\
\text { Sensitive to pH. Below } 6.5 \text { or above } 7.5 \text { reduces activity or } \\
\text { increases noxious odors. } \\
\text { Can irritate skin and damage mucous membranes. }\end{array}$ \\
\hline Chlorine Dioxide & $\begin{array}{l}\text { Activity is much less } \mathrm{pH} \text { dependent } \\
\text { than chlorine. }\end{array}$ & $\begin{array}{l}\text { Must be generated on-site. } \\
\text { Greater human exposure risk than chlorine. Off-gassing of } \\
\text { noxious gases is common. } \\
\text { Concentrated gases can be explosive. }\end{array}$ \\
\hline Peroxyacetic acid & $\begin{array}{l}\text { No known toxic residues or byproducts. } \\
\text { Produces very little off-gassing. } \\
\text { Less affected by organic matter than chlorine. } \\
\text { Low corrosiveness to equipment. }\end{array}$ & $\begin{array}{l}\text { Activity is reduced in the presence of metal ions. } \\
\text { Concentrated product is very toxic to humans. } \\
\text { Sensitive to } \mathrm{pH} \text {. Greatly reduced activity at pH } \\
\text { above 7-8. }\end{array}$ \\
\hline Ozone & $\begin{array}{l}\text { Very strong oxidizer/sanitizer. } \\
\text { Can reduce pesticide residues in the water. } \\
\text { Less sensitive to } \mathrm{pH} \text { than chlorine (but breaks } \\
\text { down much faster above } \sim \mathrm{pH} 8.5 \text { ). } \\
\text { No known toxic residues or byproducts. }\end{array}$ & $\begin{array}{l}\text { Must be generated on-site. } \\
\text { Ozone gas is toxic to humans. Off-gassing can be a problem. } \\
\text { Treated water should be filtered to remove particulates and } \\
\text { organic matter. } \\
\text { Very corrosive to equipment (including rubber and some } \\
\text { plastics). } \\
\text { Highly unstable in water - half life } 15 \text { minutes; may be less } \\
\text { than } 1 \text { minute in water with organic matter or soil. }\end{array}$ \\
\hline \multicolumn{3}{|c|}{$\begin{array}{l}\text { Note: Although quaternary ammonia is an effective sanitizer with useful properties and can be used to sanitize equipment, it is not } \\
\text { registered for contact with food. }\end{array}$} \\
\hline
\end{tabular}

from chlorine-generated THMs on the surface of fresh horticultural produce is extremely low.

Chlorine dioxide $\left(\mathrm{ClO}_{2}\right)$. Chlorine dioxide is a synthetically produced yellowish-green gas with an odor like chlorine. Chlorine dioxide is typically used at concentrations between 1 and 5 ppm. However, it usually must be generated on-site because the concentrated gas can be explosive and decomposes rapidly when exposed to light or temperatures above $50^{\circ} \mathrm{C}\left(122^{\circ} \mathrm{F}\right)$. These concentrated gases also poses a greater risk to workers than sodium or calcium hypochlorite. Noxious odors from off-gassing can be a common problem, especially at higher concentrations, which restricts its use to well-ventilated areas away from workers. Unlike chlorine, $\mathrm{ClO}_{2}$ does not hydrolyze in water and is virtually unaffected by $\mathrm{pH}$ changes between 6 to 10 and does not react with organic matter to form THMs. However, $\mathrm{ClO}_{2}$ may produce other potentially hazardous byproducts (e.g. chlorate and chlorite). One additional drawback is that no simple assays to monitor $\mathrm{ClO}_{2}$ concentration are currently available.

Peroxyacetic acid (PAA). Peroxyacetic acid (e.g. Tsunami $\left.{ }^{\circledR}\right)$ is a strong oxidizer formed from hydrogen peroxide and acetic acid. The concentrated product $(40 \%$ PAA) has a pungent odor and is highly toxic to humans. PAA is very soluble in water with very little off-gassing and it leaves no known toxic breakdown products or residue on the produce. Unlike chlorine and ozone, it has good stability in water containing organic matter, which can greatly increase the longevity of the sanitizer, and it is not corrosive to equipment. PAA is most active in acidic environments with $\mathrm{pH}$ between 3.5 and 7 , but activity declines rapidly above $\mathrm{pH} 7-8$. High temperatures and metal ion contamination will also reduce its activity.

Ozone (03). Ozone is a water-soluble gas formed by splitting $\mathrm{O}_{2}$ (with electricity or UV light) that further reacts other $\mathrm{O}_{2}$ to form $\mathrm{O}_{3}$. Ozone gas is one of the strongest oxidizing agents and sanitizers available and is highly corrosive to equipment including rubber, some plastics, and fiberglass. An expert panel declared $\mathrm{O}_{3}$ to be Generally Recognized As Safe (GRAS) in 1997 and O3 is currently legal for food contact applications. Although $\mathrm{O}_{3}$ is not particularly soluble in water $\left(30 \mathrm{ppm}\right.$ at $\left.20^{\circ} \mathrm{C}\right)$, concentrations of 0.5 to $2 \mathrm{ppm}$ are effective against pathogens in clean water with no soil or organic matter. In practice, even concentrations of $10 \mathrm{ppm}$ are difficult to obtain and concentrations of $5 \mathrm{ppm}$ or less are more common. There have been reports that $\mathrm{O}_{3}$ may induce resistance to subsequent fungal attacks in some horticultural products.

Ozone decomposes quickly in water with a half-life of 15 to 20 minutes in clean water but less than 1 minute in water containing suspended soil particles and organic matter. Thus, ozonated water should be filtered to remove these particulates. Cooler temperatures of hydrocoolers may also extend ozone's half-life. The antimicrobial activity of $\mathrm{O}_{3}$ is stable between $\mathrm{pH} 6$ and 8 but decomposes more rapidly at higher $\mathrm{pH}$. Ozone breaks down to $\mathrm{O}_{2}$ and no other toxic by-products have been reported. Ozone efficacy is diminished when dissolved iron, manganese, 
copper, nickel, hydrogen sulfide, or ammonia are present in the solution.

Because of its strong oxidizing potential, $\mathrm{O}_{3}$ is toxic to humans and must be generated on-site. Prolonged exposure to more than 4 ppm $\mathrm{O}_{3}$ in air can be lethal. Ozone has a pungent odor that can be detected by humans at 0.01 to 0.04 ppm. OSHA has set worker safety limits in air of 0.1 ppm exposure over an 8 hour period and 0.3 ppm over a 15 minute period. At concentrations in water above 1 ppm, off-gassing can result in concentrations in the air that exceed OSHA limits of $0.1 \mathrm{ppm}$.

\section{Shipping Containers and Palletization}

The selection and use of appropriately designed shipping containers have long been a concern to fresh produce shippers. In addition to serving as a uniform measure of quantity, a properly designed container must protect the product during handling, allow sufficient ventilation during cooling and storage, and facilitate palletization.

A common mistake is to purchase containers on the basis of cost rather than stacking strength, resulting in failure during shipping and storage. The container must be constructed of material with sufficient strength so that the package, rather than the product, bears the weight of the stacked pallet. Corrugated fiberboard cartons must be protected from direct contact with water during handling shipping and warehousing. While providing excellent protection from wet environments, waxing renders the cartons difficult to recycle. Wooden wirebound crates work well under wet conditions, such as hydrocooling, but must be carefully stacked so as to use the sturdy end panels. Stacking on the side panels should be avoided since these have little strength. Inner surfaces of the container should be smooth and free of sharp, protruding and abrasive edges.

Ventilation is critical for efficient removal of field heat during cooling and for maintenance of product temperature during handling and storage. Containers should be designed with vent holes large enough to maximize airflow. Cooling will be discussed in greater detail in the following section.

Unitizing produce shipping containers (palletization) promotes efficiency in the distribution system - mechanical injury is reduced by eliminating transfers and by reducing the number of shipping container sizes. The movement toward palletization led to the development of standardized container sizes by European, and later American and Canadian, produce associations. The result was container sizes designed to cover $100 \%$ of the surface area of a standard-sized pallet measuring 100 by 120 centimeters, or approximately 40 by 48 inches. During the past 10 years, the $40 \times 48$-inch pallet has become the standard pallet used in the North American produce industry. The footprint
Table 3. Standardized shipping container dimensions designed for a 40 x 48-inch pallet.

\begin{tabular}{|c|c|c|c|}
\hline \multicolumn{2}{|c|}{$\begin{array}{c}\text { Outside Base } \\
\text { Dimensions }\end{array}$} & \multirow[b]{2}{*}{$\begin{array}{l}\text { Containers } \\
\text { Per Layer }\end{array}$} & \multirow[b]{2}{*}{$\begin{array}{l}\text { Layers can be } \\
\text { Cross-Stacked }\end{array}$} \\
\hline $\begin{array}{l}\text { S.I. } \\
\text { Units }\end{array}$ & $\begin{array}{l}\text { English } \\
\text { Units }\end{array}$ & & \\
\hline $40 \times 30 \mathrm{~cm}$ & $15^{3 / 4} \times 11^{3 / 4}$ in & 10 & Yes \\
\hline $50 \times 30 \mathrm{~cm}$ & $19^{3} / 4 \times 11^{3} / 4$ in & 8 & No \\
\hline $50 \times 40 \mathrm{~cm}$ & $19^{3 / 4} \times 15^{3 / 4}$ in & 6 & No \\
\hline $60 \times 40 \mathrm{~cm}$ & $23 \frac{3}{4} \times 15^{3 / 4}$ in & 5 & Yes \\
\hline
\end{tabular}

(base dimensions) of these standardized containers accommodate $5,6,8$ or 10 containers per layer on the standard pallet (Table 3). Recently, shippers are being encouraged to use only two shipping containers sizes, 5 or 10 containers per layer. In all of these standardized container footprints, the volume for the specific crop is determined by adjusting the carton height.

Several years ago the Florida tomato and strawberry industries led the way by adopting standardized shipping cartons and palletization. Beginning in the mid-1990s Florida vegetable shippers began incorporating standardized dimensions and other vent-alignment design features recommended by UF/IFAS into their shipping containers (Fig. 18-2A and Fig. 18-2B).

With increasing emphasis on reduction of the waste stream, shippers should consider packing their vegetables in containers that are returnable or recyclable by receivers. For example, some markets refuse to accept produce packed in waxed, corrugated cartons. Similarly, wooden wirebound crates are not easily recyclable but are often reused by smaller produce handlers at destination markets. Recyclable containers can be fabricated from fiberboard or plastic with the cost included in the selling price of the product. Returnable containers are in wide use in Europe, and there is increasing interest on the part of shippers and receivers in North America. These containers are constructed of rigid plastic, have exceptional useful life, can be sanitized, and can be designed for excellent ventilation. Return is facilitated through a collapsible design feature. Returnable containers are leased. Recently, leased pallets have become widely available throughout the U.S. and Canada and are competitively priced with purchased pallets. Leased pallets have many advantages in that the supplier maintains a pool of pallets that are clean and in excellent repair. 


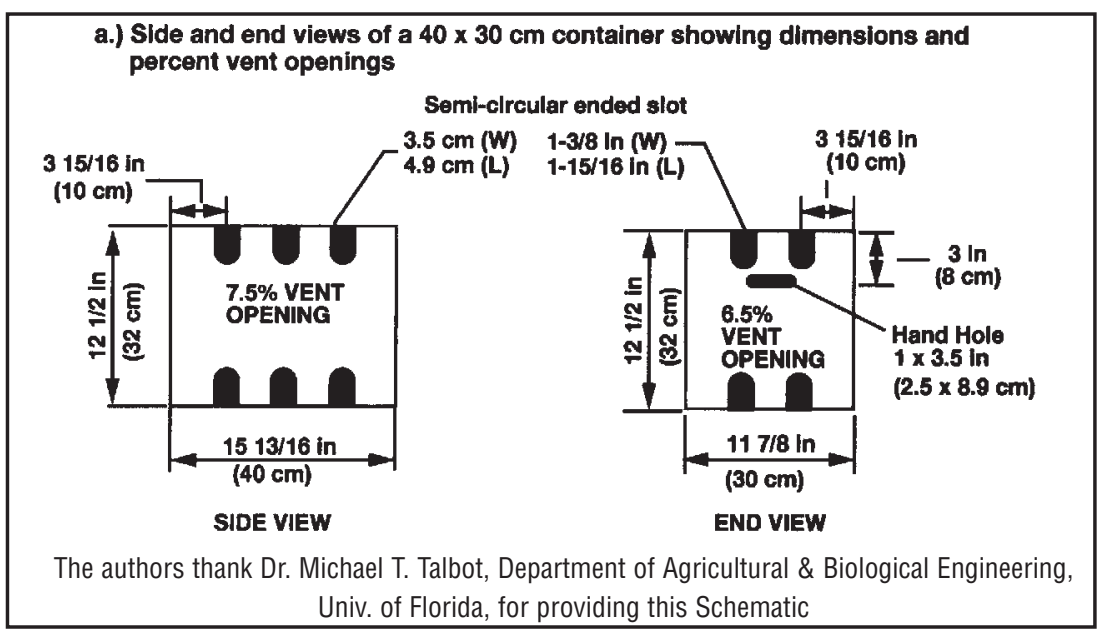

Fig. 18-2A. Dimensions of a standardized (MUM) produce shipping container (40 $\mathrm{x}$ $30 \mathrm{~cm}$ base) showing alignment of vertical openings for optimal cooling.

b.) Top view of pallet showing cross-stacked layer and matching vent openings.

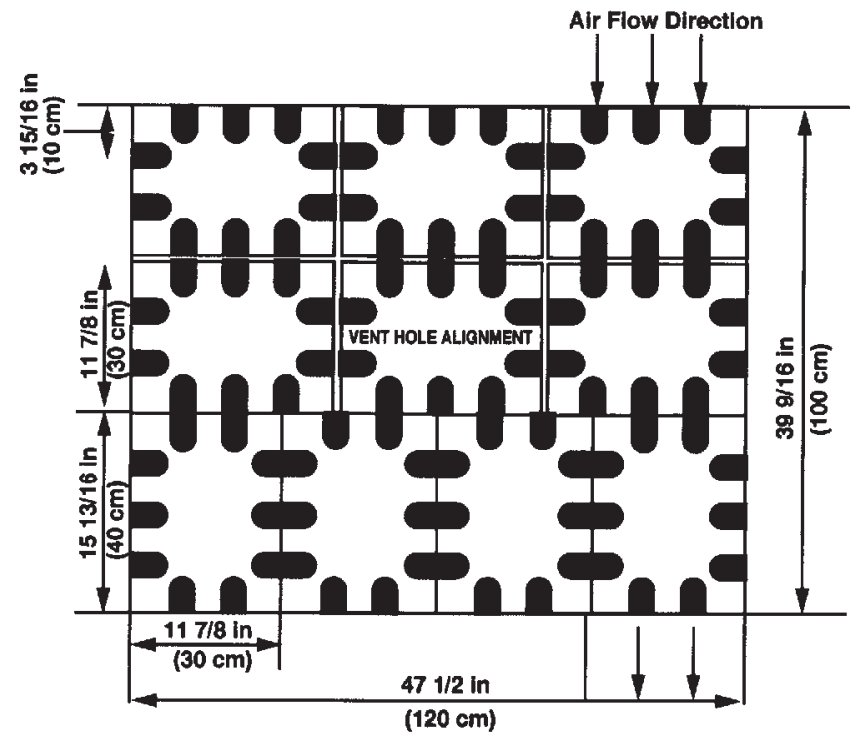

The authors thank Dr. Michael T. Talbot, Department of Agricultural \& Biological Engineering Univ. of Florida, for providing this Schematic

Fig. 18-2B. Dimensions of a standardized (MUM) produce shipping container (40 $\mathrm{x}$ $30 \mathrm{~cm}$ base) showing alignment of vertical openings for optimal cooling.

$\mathrm{CO}_{2}$ and other products. The respiration rate varies by commodity; those commodities with high respiration rates utilize the reserves faster and are more perishable than those with lower respiration rates. Therefore, vegetables with higher respiration rates, such as broccoli and sweetcorn, must be rapidly cooled to the optimal storage temperature to slow metabolism and extend postharvest life during subsequent shipping and handling operations.

Since the introduction of hydrocooling for celery in the 1920s, rapid cooling (precooling) has allowed Florida produce to be shipped to distant markets while maintaining high quality. Commercial cooling is defined as the rapid removal of field heat to temperatures approaching optimal storage temperature and it is the first line of defense in retarding the biological processes that reduce vegetable quality. Cooling, in conjunction with refrigeration during subsequent handling operations, provides a "cold chain" from packinghouse to supermarket to maximize postharvest life and control disease and pests. (The term "postharvest life" is purposely used in this text, since "shelf life" has the connotation that the commodity "sits on the shelf", implying that the product requires no subsequent refrigeration.) Timeliness during handling is also essential in maintaining produce quality: timely and careful harvest and transport to the packinghouse, rapid packing and cooling, and rapid transport to the market or buyer. Everyone involved at each of the many steps during product handling (e.g., shippers, truckers, receivers) must take care to ensure that the refrigerated cold chain is not broken.

\section{TEMPERATURE MANAGEMENT}

\section{Importance}

Once harvested, a vegetable continues life processes independent of the plant, and as a result, must utilize its own stored energy reserves. Within hours of harvest, crops held at ambient temperatures can suffer irreversible losses in quality, reducing postharvest life. Additionally, many vegetables, such as greens, celery and lettuce, are cut at harvest, and this wound further increases stress on the tissue. The relative perishability of a crop is reflected in its respiration rate, where respiration is the process of life by which $\mathrm{O}_{2}$ is combined with stored carbohydrates and other components to produce heat, chemical energy, water,
Many Florida shippers are well equipped to rapidly cool their crops, and a growing number are incorporating cooling or improving their existing facilities. Simple placement of packed vegetables in a refrigerated cooler is not sufficient to maintain quality for product destined for distant markets. Neither should non-cooled vegetables be loaded directly into refrigerated trailers. In both of these situations the product cools very slowly, at best. Refrigerated trailers are designed to maintain product temperature during transport, and they do not have the refrigeration capacity to quickly remove field heat. Therefore, only produce that has been properly cooled should be loaded, and only into trailers that have been cooled prior to loading. 


\section{Storage Requirements}

Horticultural crops may be grouped into two broad categories based on sensitivity to storage temperatures. The degree of chilling sensitivity, and therefore the lowest safe storage temperature, is crop-specific. Those crops that are chilling sensitive should be held at temperatures generally above $50^{\circ} \mathrm{F}\left(10^{\circ} \mathrm{C}\right)$. Storage below this threshold will give rise to a physiological disorder known as chilling injury. Chilling injury symptoms are characterized by development of sunken lesions on the skin, increased susceptibility to decay, increased shrivel, and incomplete ripening (poor flavor, texture, aroma and color). Those crops not as sensitive to chilling injury may be stored at temperatures as low as $32^{\circ} \mathrm{F}\left(0^{\circ} \mathrm{C}\right)$. The extent of chilling symptoms is also dependent on the length of exposure to low temperatures. Short exposure times will result in less injury than longer exposure to chilling temperatures.

In addition to maintaining storage rooms at proper storage temperatures, the relative humidity should also be controlled to reduce water loss from the crop. Optimal storage recommendations and precooling methods are included for a wide range of vegetable commodities (Table 4). Handling recommendations for roadside markets have also been developed. (See Vegetable Crops Fact Sheet VC-33, Produce Handling for Roadside Markets).

Table 4. Recommended storage conditions and cooling methods for maximum postharvest life of commercially grown vegetables.

\begin{tabular}{|c|c|c|c|c|c|}
\hline \multirow[b]{2}{*}{ Commodity } & \multicolumn{2}{|c|}{ Temperature } & \multirow{2}{*}{$\begin{array}{c}\text { Relative } \\
\text { Humidity (\%) }\end{array}$} & \multirow{2}{*}{$\begin{array}{l}\text { Approximate } \\
\text { Storage Life }\end{array}$} & \multirow[b]{2}{*}{ Cooling Method ${ }^{1}$} \\
\hline & ${ }^{\circ} \mathrm{F}$ & ${ }^{\circ} \mathrm{C}$ & & & \\
\hline Artichoke, globe & 32 & 0 & $95-100$ & 2-3 weeks & HY, ROOM \\
\hline Artichoke, Jerusalem & $31-32$ & $-0.5-0$ & $90-95$ & $4-5$ months & ROOM \\
\hline Asparagus & $32-35$ & $0-2$ & $95-100$ & 2-3 weeks & HY \\
\hline Bean, dry & $40-50$ & $4-10$ & $40-50$ & $6-10$ months & ROOM \\
\hline Bean, green or snap & $40-45$ & $4-7$ & 95 & $7-10$ days & HY, FA \\
\hline Bean, lima & $37-41$ & $3-5$ & 95 & 5-7 days & HY \\
\hline Bean sprout & 32 & 0 & $95-100$ & 7-9 days & ROOM \\
\hline Beet, bunched & 32 & 0 & $98-100$ & $10-14$ days & HY \\
\hline Beet, topped & 32 & 0 & $98-100$ & 4-6 months & ROOM \\
\hline Broccoli & 32 & 0 & $95-100$ & $10-14$ days & HY, ICE \\
\hline Brussels sprout & 32 & 0 & $95-100$ & 3-5 weeks & HY,VAC \\
\hline Cabbage, early & 32 & 0 & $98-100$ & 3-6 weeks & ROOM \\
\hline Cabbage, late & 32 & 0 & $98-100$ & 5-6 months & ROOM \\
\hline Cabbage, Chinese & 32 & 0 & $95-100$ & $2-3$ months & HY,VAC \\
\hline Carrot, bunched & 32 & 0 & $95-100$ & 2 weeks & HY \\
\hline Carrot, mature, topped & 32 & 0 & $98-100$ & 7-9 months & HY \\
\hline Carrot, immature, topped & 32 & 0 & $98-100$ & 4-6 weeks & $\mathrm{HY}$ \\
\hline Cassava, (yuca) ${ }^{2}$ & $32-41$ & $0-5$ & $85-90$ & 1-2 months & ROOM \\
\hline Cauliflower & 32 & 0 & $95-98$ & 3-4 weeks & HY,VA \\
\hline Celeriac & 32 & 0 & $97-99$ & 6-8 months & ROOM \\
\hline Celery & 32 & 0 & $98-100$ & $2-3$ months & HY,VAC \\
\hline Chard & 32 & 0 & $95-100$ & $10-14$ days & HY,ICE,VAC \\
\hline Chayote & 45 & 8 & $85-90$ & 4-6 weeks & ROOM \\
\hline Chicory, witloof, Belgian endive & 32 & 0 & $95-100$ & 2-4 weeks & HY,ICE,VAC \\
\hline Collard & 32 & 0 & $95-100$ & $10-14$ days & HY,ICE,VAC \\
\hline Corn, sweet & 32 & 0 & $95-98$ & 5-8 days & HY,ICE,VAC \\
\hline Cucumber & $50-55$ & $10-13$ & 95 & $10-14$ days & HY \\
\hline Eggplant & $46-54$ & $8-12$ & $90-95$ & 1 week & FA \\
\hline Endive and escarole & 32 & 0 & $95-100$ & 2-3 weeks & HY,ICE,VAC \\
\hline Garlic & 32 & 0 & $65-70$ & 6-7 months & ROOM \\
\hline Ginger & 55 & 13 & 65 & 6 months & ROOM \\
\hline Greens, leafy & 32 & 0 & $95-100$ & 10-14 days & HY,ICE,VAC \\
\hline Horseradish & $30-32$ & $-1.0-0$ & $98-100$ & 10-12 months & ROOM \\
\hline Jicama & $55-65$ & $13-18$ & $65-70$ & $1-2$ months & ROOM \\
\hline Kale & 32 & 0 & $95-100$ & 2-3 weeks & HY,ICE,VAC \\
\hline Kohlrabi & 32 & 0 & $98-100$ & 2-3 months & ROOM \\
\hline Leek & 32 & 0 & $95-100$ & $2-3$ months & HY,ICE,VAC \\
\hline Lettuce & 32 & 0 & $98-100$ & $2-3$ weeks & VAC \\
\hline Malanga $^{2}$ & 50 & 10 & $90-95$ & 4-5 months & ROOM \\
\hline \multicolumn{6}{|l|}{ Melon } \\
\hline Cantaloupe (3/4-slip) & $36-41$ & $2-5$ & 95 & 15 days & $\mathrm{FA}, \mathrm{HY}$ \\
\hline Cantaloupe (full-slip) & $32-36$ & $0-2$ & 95 & $5-14$ days & FA,HY,ICE \\
\hline
\end{tabular}


Table 4. Continued.

\begin{tabular}{|c|c|c|c|c|c|}
\hline \multirow[b]{2}{*}{ Commodity } & \multicolumn{2}{|c|}{ Temperature } & \multirow{2}{*}{$\begin{array}{c}\text { Relative } \\
\text { Humidity (\%) }\end{array}$} & \multirow{2}{*}{$\begin{array}{l}\text { Approximate } \\
\text { Storage Life }\end{array}$} & \multirow[b]{2}{*}{ Cooling Method ${ }^{1}$} \\
\hline & ${ }^{\circ} \mathrm{F}$ & & & & \\
\hline \multicolumn{6}{|l|}{ Melon (continued) } \\
\hline Casaba & 50 & 10 & $90-95$ & 3 weeks & ROOM \\
\hline Crenshaw & 45 & 7 & $90-95$ & 2 weeks & ROOM \\
\hline Honey Dew & 45 & 7 & $90-95$ & 3 weeks & ROOM \\
\hline Persian & 45 & 7 & $90-95$ & 2 weeks & ROOM \\
\hline Watermelon & $50-60$ & $10-15$ & 90 & 2-3 weeks & ROOM \\
\hline Mushroom & 32 & 0 & 95 & 3-4 days & FA,VAC \\
\hline Okra & $45-50$ & $7-10$ & $90-95$ & $7-10$ days & FA \\
\hline Onion, green & 32 & 0 & $95-100$ & 3-4 weeks & HY,ICE \\
\hline Onion, dry ${ }^{2}$ & 32 & 0 & $65-70$ & 1-8 months & ROOM \\
\hline Onion sets & 32 & 0 & $65-70$ & 6-8 months & ROOM \\
\hline Parsley & 32 & 0 & $95-100$ & 2-2.5 months & HY,ICE \\
\hline Parsnip & 32 & 0 & $98-100$ & 4-6 months & ROOM \\
\hline Pea, green & 32 & 0 & $95-98$ & 1-2 weeks & HY,ICE \\
\hline Pea, southern & $40-41$ & $4-5$ & 95 & 6-8 days & HY \\
\hline Pepper, chili (dry) & $32-50$ & $0-10$ & $60-70$ & 6 months & ROOM \\
\hline Pepper, sweet (bell) & $45-55$ & $7-13$ & $90-95$ & 2-3 weeks & FA \\
\hline Potato, early crop ${ }^{2}$ & 40 & 4 & $90-95$ & 4-5 months & HY,ROOM \\
\hline Potato, late crop ${ }^{2}$ & 40 & 4 & $90-95$ & 5-10 months & ROOM \\
\hline Pumpkin & $50-55$ & $10-13$ & $50-70$ & 2-3 months & ROOM \\
\hline Radish, spring & 32 & 0 & $95-100$ & 3-4 weeks & HY \\
\hline Radish, winter & 32 & 0 & $95-100$ & 2-4 months & ROOM \\
\hline Rhubarb & 32 & 0 & $95-100$ & 2-4 weeks & HY,ROOM \\
\hline Rutabaga & 32 & 0 & $98-100$ & 4-6 months & ROOM \\
\hline Salsify & 32 & 0 & $95-98$ & 2-4 months & ROOM \\
\hline Spinach & 32 & 0 & $95-100$ & $10-14$ days & ICE,HY,VAC \\
\hline Squash, summer & $41-50$ & $5-10$ & 95 & $1-2$ weeks & FA, HY \\
\hline Squash, winter & 50 & 10 & $50-70$ & dep on type & ROOM \\
\hline Strawberry & 32 & 0 & $90-95$ & 5-7 days & FA \\
\hline Sweet potato, boniato ${ }^{2}$ & $55-60$ & $13-16$ & $85-90$ & 4-7 months & ROOM \\
\hline Tamarillo & $37-40$ & $3-4$ & $85-95$ & 10 weeks & ROOM \\
\hline Taro (Dasheen)² & $45-50$ & $7-10$ & $85-90$ & 4-5 months & ROOM \\
\hline Tomato, mature-green & $55-70$ & $13-21$ & $90-95$ & 1-3 weeks & FA,ROOM \\
\hline Tomato, firm red (stage 6) & $46-50$ & $8-10$ & $90-95$ & 4-7 days & FA,ROOM \\
\hline Turnip & 32 & 0 & 95 & 4-5 months & ROOM \\
\hline Turnip greens & 32 & 0 & $95-100$ & $10-14$ days & HY,ICE,VAC \\
\hline Waterchestnut & $32-36$ & $0-2$ & $98-100$ & 1-2 months & ROOM \\
\hline Watercress & 32 & 0 & $95-100$ & 2-3 weeks & HY,ICE,VAC \\
\hline $\mathrm{Yam}^{2}$ & 61 & 16 & $70-80$ & 6-7 months & ROOM \\
\hline
\end{tabular}

\section{OPTIMIZING COMIMERCIAL COOLING}

\section{Cooling Concepts}

Cooling is a term that is often used quite loosely. In order to be effective and significantly benefit the shipping life of the product, an appropriate definition of commercial cooling for perishable crops is: The rapid removal of at least $7 / 8$ of the field heat from the crop by a compatible cooling method. The time required to remove $7 / 8$ of the field heat is known as the 7/8 Cooling Time. Removal of $7 / 8$ of the field heat during cooling is strongly recommended to provide adequate shipping life for shipment to distant markets; also, 7/8 of the heat can be removed in a fairly short amount of time. Removal of the remaining $1 / 8$ of the field heat will occur during subsequent refrigerated storage and handling with little detriment to the product.

The rate of heat transfer, or the cooling rate, is critical for efficient removal of field heat in order to achieve cooling. As a form of energy, heat always seeks equilibrium. In the case of cooling, the sensible heat (or field heat) from the product is transferred to the cooling medium. The efficiency of cooling is dependent on time, temperature and contact. In order to achieve maximum cooling, the product must remain in the precooler for sufficient time to remove heat. The cooling medium (air, water, crushed ice) must be maintained at constant temperature throughout the cooling period. The cooling medium also must have continuous, intimate contact with the surfaces of the individual vegetables. For 
reasonable cooling efficiency, the cooling medium temperature should be at least at the recommended storage temperature for the commodity found in Table 4. Inappropriately designed containers with insufficient vent or drain openings or incorrectly stacked pallets can markedly restrict the flow of the cooling medium, increasing cooling time.

\section{COOLING METHODS}

The cooling rate is not only dependent upon time, temperature and contact with the commodity; it is also dependent upon the cooling method being employed. The various cooling media used to cool produce have different capacities to remove heat.

\section{Room Cooling}

The simplest, but slowest, cooling method is room cooling, in which the bulk or containerized commodity is placed in a refrigerated room for several days. Air is circulated by the existing fans past the evaporator coil to the room. Vented containers and proper stacking are critical to minimize obstructions to air flow and ensure maximum heat removal. Room cooling is not considered precooling and is satisfactory only for commodities with low respiration rates, such as mature potatoes, dried onions and cured sweetpotatoes. Under certain circumstances these latter crops may require precooling, such as when harvested under high ambient temperatures.

\section{Forced-Air (Pressure) Cooling}

The cooling efficiency of refrigerated rooms can be greatly improved by increasing the airflow through the product. This principle led to the development of forcedair, or pressure cooling, in which refrigerated room air is drawn at a high flow rate through specially stacked containers or bins by means of a high capacity fan. This method can cool as much as four times faster than room cooling. In many cases, cold storage rooms can be retrofitted for forced-air cooling, which requires less capital investment than other precooling methods (Fig. 18-3). However, in order to achieve such rapid heat removal, the refrigeration capacity of the room may need to be increased in order to be able to maintain the desired air temperature during cooling. Portable systems can be taken to the field (Fig. 18-4).

With either room cooling or forced-air cooling, precautions must be taken to minimize water loss from the product. The refrigeration system actually dehumidifies the cold-room air as water vapor in the air condenses on the evaporator coil. This condensation lowers the relative humidity in the room, creating a greater vapor pressure deficit between the product and the surrounding air. As a result the product loses moisture to the air. To minimize water loss during cooling and storage, the ambient relative humidity should be maintained at the recommended level for the particular crop (commercial humidification systems are available) and the product should be promptly removed from the forced-air precooler upon achieving 7/8 Cooling. Forced-air cooling is recommended for most of the fruittype vegetables and is especially appropriate for vegetables such as peppers and tomatoes that are susceptible to infiltration of water-borne decay organisms.

\section{Hydrocooling}

Hydrocooling removes heat at a faster rate than forcedair cooling. The heat capacity of refrigerated water is greater than that for air, which means that a given volume of water can remove more heat than the same volume of air at the same temperature. Hydrocooling is beneficial in that it does not remove water from the commodity. It is most efficient (and, therefore, most rapid) when individual vegetables are cooled by immersion in flumes or by overhead drench, since the water completely covers the product surfaces. Cooling becomes less efficient when the commodity is hydrocooled in closed containers, and even less efficient when containers are palletized and hydrocooled. It is important to continuously monitor the hydrocooler water and product temperatures and adjust the residence time of the product in the hydrocooler accordingly in order to achieve thorough cooling.

Sanitation of the hydrocooling water is critical, since it is recirculated. Decay organisms present on the vegetables can accumulate in the water, inoculating subsequent product being hydrocooled. Cooling water should be changed frequently. Commodities that are hydrocooled must be sufficiently resistant to withstand the force of the water drench. The container must also have sufficient strength so as to resist application of water. Crops recommended for hydrocooling include sweetcorn, snap beans, cucumbers and summer squash.

\section{Contact Icing}

Contact icing has been used for both cooling and temperature maintenance during shipping. Heat from the product is absorbed by the ice, causing it to melt. As long as the contact between the ice and produce is maintained, cooling is fairly rapid and the melted ice serves to maintain a very high humidity level in the package, which keeps the produce fresh and crisp. Non-uniform distribution of ice reduces the cooling efficiency. There are two types of contact icing: top icing and package icing.

Top icing involves placement of crushed ice over the top layer of product in a container prior to closure. Although relatively inexpensive, the cooling rate can be fairly slow since the ice only directly contacts the product on the top layer. For this reason, it is recommended that top icing be applied after precooling to crops with lower respiration rates such as leafy vegetables and celery but not for fruit of warm - season crops (Fig. 18-5). Prior to shipping, ice is blown on top of containers loaded in truck trailers to aid 
in cooling and maintenance of higher relative humidity. However, care should be taken to avoid blockage of vent spaces in the load; this restricts airflow, which results in warming of product in the center of the load during shipment. Ice should also be "tempered" with water to bring the temperature to $32^{\circ} \mathrm{F}\left(0^{\circ} \mathrm{C}\right)$ to avoid freezing of the product.

Package Icing. Crushed ice distributed within the container is known as package icing. Cooling is faster and more uniform than for top icing, but it can be more labor intensive to apply.

A modified version of package icing utilizes a slurry of refrigerated water and finely chopped ice drenched over either bulk or containerized produce or injected into side hand holds. This "slush ice" method has been widely adopted for commodities tolerant to direct contact with water and requiring storage at $32^{\circ} \mathrm{F}\left(0^{\circ} \mathrm{C}\right)$. The water acts as a carrier for the ice so that the resulting slush, or slurry, can be pumped into a packed container. The rapidly flowing slush causes the product in the container to float momentarily until the water drains out the bottom. As the product settles in the container, the ice encases the individual vegetables by filling air voids, thus providing good contact for heat removal. Slush icing is somewhat slower than forced-air cooling, but it does reduce pulp temperatures to $32^{\circ} \mathrm{F}\left(0^{\circ} \mathrm{C}\right)$ within a reasonable amount of time and maintains a high relative humidity environment. Container selection is critical. The container must be oversized to accommodate sufficient ice to provide cooling. Corrugated fiberboard cartons must be resistant to contact with water (usually impregnated with paraffin wax) and must be of sufficient strength so as not to deform. Shipping operations must also tolerate water dripping from the melting ice during handling and storage. Package icing is successfully used for leafy crops, sweetcorn, green onions and cantaloupes.

\section{Vacuum Cooling}

Vacuum cooling is a very rapid method of cooling, and is most efficient for commodities with a high surface-tovolume ratio such as leafy crops (Fig. 18-6). This method is based on the principle that, as the atmospheric pressure is reduced, the boiling point of water lowers. Containerized or bulk product is thoroughly wetted, placed in a vacuum chamber (tube) and sealed. The pressure in the chamber is reduced until the water on the product surface boils at the desired precooling temperature. As water on the product surface evaporates, it removes field heat; the resultant vapor is condensed on evaporator coils within the vacuum tube to increase cooling efficiency. Any water that evaporates from the vegetable tissue is removed uniformly throughout the product. Therefore, it does not tend to result in visible wilting in most cases.
Precautions must be taken so as not to cool the products below their chilling temperature threshold. Vacuum coolers are costly to purchase and operate and are normally used only in high volume operations or are shared among several growers. Commodities that can be cooled readily by vacuum cooling include leafy crops, such as spinach, lettuce, collards and celery.

When selecting an appropriate cooling method, several factors must be considered, including: the maximum volume of product requiring precooling on a given day, the compatibility of the method with the commodities to be cooled, subsequent storage and shipping conditions, and fixed/variable costs of the system. (For more information regarding selection of a cooling system, see SSVEC-47, Evaluating Precooling Methods for Vegetable Packinghouse Operations)

\section{SUMMARY}

Through careful attention to postharvest handling, high quality vegetables can be successfully shipped to distant markets. Two principal means for extending postharvest life are: minimizing mechanical injury during handling and rapidly removing field heat within a few hours of harvest. Standardized shipping containers of sturdy materials should be used to facilitate cooling and palletization. Successful implementation of an appropriate cooling method into an operation requires thorough evaluation of each of the components in the handling system.

\section{ADDITIONAL RESOURCES}

Mahovic, Michael, Steven A. Sargent, and Jerry A. Bartz. 2002. Guide to Identifying and Controlling Postharvest Tomato Diseases in Florida. EDIS Publication HS866. Horticultural Sciences Department, Florida Cooperative Extension Service, Institute of Food and Agricultural Sciences, University of Florida. EDIS Web site at http://edis.ifas.ufl.edu.

Sargent, S.A., M.T. Talbot and J.K. Brecht. Evaluating precooling methods for vegetable packinghouse operations. Vegetable Crops Dept., University of Florida, Gainesville. SSVEC-47. April 1991. 13 p.

Talbot, M.T. and C.D. Baird. Evaluating commercial forced-air precoolers. Proc. Florida State Horticultural Society. 103:218-221.

(Florida Cooperative Extension Service Fact Sheets) 